doing so examine our evolution in the management of MCI. Recommendations based on deficiencies in management and limitations felt are addressed. We infer that comparison of the four events will help our institution formulate a better plan to deal with future MCI and suggest a similar review for such incidents.

\section{MASS CASUALTY INCIDENTS - EVOLUTION OF MANAGEMENT PLAN IN A TERTIARY CARE HOSPITAL USING POST EVENT ANALYSIS}

R Sayyed*, H Zafar, M S Effendi Correspondence: Department of Surgery, The Aga Khan University Hospital, Stadium Road, Karachi 74800, Pakistan

\subsection{6/ip.2010.029215.713}

A mass casualty incident (MCI) is a challenging scenario in any healthcare setting. It puts to test the potential of a healthcare facility to perform under stress and manage utilisation of all available resources in a limited time. Over the last few years, Pakistan has been the site for many MCI secondary to terrorist bombings. The Aga Khan University Hospital having evolved as a major trauma centre of Karachi has dealt with a few of such MCI. We have reviewed four MCI over the last few years in which our hospital received patients. These incidents involved the French bombing in 2002, Hyderi Mosque Blast in 2004, Karsaz Bombing in 2007 and the most recent Ashura Procession Bombing in December 2009. Some of these events were a result of suicide bombing. We attempt to look at the injury patterns of each event and the way these incidents were dealt at our institution and in 